\title{
Facilities for computer-supported decision-making in schools: explanations for lack of use and proposals for improvement
}

\author{
A.J. Visscher \\ University of Twente, Faculty of Educational Science and \\ Technology \\ P.O. Box 217, 7500 AE Enschede, The Netherlands \\ Phone: (31)-53-4893609 \\ e-mail:Visscher@edte.utwente.nl \\ Fax: (31)-53-4893791
}

\begin{abstract}
In this paper an attempt is made to explain the fact that the power of computer-assisted school information systems to support decision-making is wasted. This is done on the basis of research findings regarding the characteristics of information handling by school managers and on the decision-making capacity of schools. In addition, some ways to promote the use of school information systems (SISs) for decision-support are presented.
\end{abstract}

Keywords

Educational management, information handling, problem solving

\section{INTRODUCTION}

This paper focuses on the support that School Information Systems (SISs) can provide when school staff make decisions and develop school policy to solve ill-structured, 'open' problems. The attempt to find solutions for structured, 'closed' problems (e.g. allocation problems like composing student lesson groups) are outside the scope of this paper.

SISs can provide various types of information that can contribute to solving unstructured school problems requiring policy-development. SIS-information can for example show:

- patterns in school results, absenteeism rates, costs, etc. and as such indicate that something needs to be done in a specific policy area. 
- relationships between phenomena (e.g. between absenteeism and student achievement, or between admission criteria and passing the final examinations).

- the probable implications of alternative policy measures (e.g. the impact of changes in student promotion criteria on student promotion).

- results of policy measures.

Although the value of computerized school information systems is being recognized worldwide, these systems are still mainly used for clerical activities carried out by school office staff and other school personnel. The extent of system usage in support of school decision-making proves to be very limited, even when sophisticated and powerful SISs are available in schools (Visscher, 1991; 1992; 1995).

In this paper explanations for this phenomenon are sought as follows. The research on information management by school managers is reviewed to give an impression of the kind of information they like and use. In addition, some general features of decisionmaking processes in educational organizations are presented that are relevant to computer-assisted decision-making. The information resulting from both activities is used for answering the two central questions of this paper: 'Why is decision-making support in schools so limited in magnitude?' and 'How can this be changed?'

\section{CHARACTERISTICS OF INFORMATION HANDLING BY SCHOOL MANAGERS}

In the view of Mintzberg (1989) managers are the nerve centres of organizational information who look for relevant internal and external information and who manipulate and disseminate the obtained information.

The information they collect concerns, among others, organizational operations, external events, ideas and trends information on pressures from consumers and interest groups. They especially look for information that is current, ('hot') and comes in the form of triggers (no aggregations but details, stimuli that illuminate). Since they communicate verbally 70-80 percent of their time, they especially like verbally transmitted information (e.g. by telephone, in meetings). Managers manipulate and restructure the information they receive, to build their own models on organizational functioning, and to benefit from it in decision-making.

The stereotype, rational, problem solving manager who takes smart decisions on the basis of all relevant information is a fairy tale (McPherson et al., 1986). Profound problem analysis and problem solving by managers are rarely found.

On the basis of a review of the literature on information handling by principals, Riehl et al. (1992) argue that the nature of the conditions under which principals work (many brief episodes of unpredictable interactions) affects their information use. Since school managers have to pay attention to so many different topics, they do not spend much time to each topic. They must react rapidly and therefore need information quickly. The objective quality of information, in terms of reliability and validity, is less important for its usage than the perceived information quality and the speed with which information becomes available. School managers prefer simple information they understand and think they can rely on and therefore like informal, verbal information. Collecting and processing formal information (e.g. information from SISs) often takes too much time and for that reason is not done very intensively (Sproull, 1981). As a consequence managers frequently take decisions without a solid information basis.

Although principals do not use computer-output very intensively, Leighwood and Montgomery (1982) in their research found that principals who frequently analyse student and teacher performance quantitatively (which nowadays is usually done in computer-assisted ways) run more effective schools. However, it is also known that school managers in general experience difficulties in using quantitative/statistical data 
because they are untrained and inexperienced in this respect (Riehl et al., 1992). The latter makes it difficult for them to determine the quality of this type of data, and to interpret and use it.

According to Mintzberg (1989) the characteristics of the information managers rely on differs from that with most formal ISs produce. The latter is aggregated, precise, internal and historical. In his opinion the formal information ISs generate is only partially used because that information is poor: it does not include qualitative information like politics, personality features, and formally non-transferrable information like gestures and tone. Formal information is too general, and since its processing takes considerable time it makes the required quick responses impossible.

A second reason for the partial use of IS-information is that political reasons may result in the distortion of IS-information, e.g. organizational staff may only provide that piece of information that strengthens their own position.

The last reason concerns the fact that human beings, when taking decisions, can only take into account a limited number of information elements as a result of their limited information processing capacity.

It can be concluded that computer-supported ISs contain only a small part of all relevant information, of which the manager receives a subset, of which the brain absorbs a subset and of which only part is precise and relevant! Much of the relevant information is in human instead of in computerized memories. This implies that printed/written as well as verbal information channels have to be used (see Sproull and Zubrow, 1981).

The research on information management by school managers may be summarized as follows:

School managers take many decisions, are burdened with information and have little time to process all information and to reflect on it. Full rational behaviour in terms of choosing the best action to achieve a goal, after processing all relevant information, is exceptional. As a result information processing is reduced and information is only used selectively. Many school management actions are uninformed or based on inaccurate information. School managers have a strong preference for information that comes quickly, is informal, understood and that triggers action. The perceived information quality, rather than its objective quality, determines the extent to which certain information is used.

\section{THE DECISION-MAKING CAPACITY OF SCHOOLS}

How schools function as organizations before a SIS is available, especially in terms of their decision-making capacity, also affects their SIS-usage in support of school policymaking.

In the literature on decision-making in educational organizations it is often argued that policy-making at school level is limited as a result of the political interests of those who participate in decision-making processes. In non-profit organizations decision-making situations are often used as 'garbage cans' in which participants throw their own, instead of organizational problems and goals (Cohen et al., 1972). This political process makes taking decisions very difficult, and in many instances leads to decisions that neither threaten any participant nor solve a problem.

Another factor weakening the decision-making power of schools concerns the difficulty to determine cause of and remedy for observed problems. The latter is due to the fact that so many factors play a role (e.g. in case of poor educational results the features of students, teachers, home features, societal patterns) and that their precise influence is uncertain. 'What causes what?' and 'What should be done to achieve or prevent something?' is therefore very difficult to say.

The partial or non-execution of decisions made (Weick, 1982) concerns another feature of school policy-making frequently mentioned in the literature. 
Until now we have spoken about schools in general terms, and we have determined some features that schools on average possess with respect to school decision-making. Although these school characteristics may be true for many schools, Marx (1975) has indicated that 'the' school does not exist. Schools vary in their policy-making capacity as a whole (school A on average is more capable in developing school policy than school B) as well as in specific areas of policy-making (school B may be a better policy-developer in policy-making field X than school $\mathrm{A}$, which performs better in field $\mathrm{Y}$ ).

The degree to which a school benefits from the facilities for computer-assisted policymaking will vary in concordance with the extent to which the prerequisites for policymaking are fulfilled in that school. Thus, if a school's policy-making capacity is small a first prerequisite for benefiting intensively from the power of SISs concerns organizational development in that school.

\section{IMPLICATIONS FOR COMPUTER-SUPPORTED DECISION-MAKING}

Although SIS-output can be very useful for school policy-making, benefiting from this form of computer-support proves to be far from easy. Information does not directly lead to decisions since decisions are the product of enormous numbers of interacting variables besides pure information (Weiss in Alkin, 1990).

That school managers do not inform their decision-making activities, by analysing trends in and relations between data or by simulating or evaluating the effects of their policy-making, may be caused by their work conditions which do not permit informed decisions, thorough reflection and evaluation (Goodlad, 1975). Using mainly information that is informal, simple, verbal, hot, quickly available and that triggers actions, they take non- or partially informed decisions as a response to this constraint in their working conditions.

Although it will not be easy to change the ways in which school managers operate, given the potential of SISs it is certainly worth trying to let them, and the schools they work in, benefit more from these tools. We should try to make their decisions as informed as possible. However, we are aware that more computer-supported school policy-making will not bring universal happiness. Computers are powerful but also have their limitations. The information they supply can for instance be too general, too old and/or inaccessible (Wild et al., 1992). SIS-information is valuable, but at the same time it is only one kind of information, and this has to be used in combination with other, more informal, types of information. Moreover, even when SISs are used in the desired ways, other school features will make full rational behaviour impossible: the role of political processes, the difficulty to find causes of and remedies for organizational problems, the non/partial execution of problems, the limited human information processing capacity, and the work conditions that make profound, informed problem analysis and problem solving impossible because managers must act quickly.

Despite all these restrictions SISs can be valuable for managing schools and therefore we will now present some proposals for increasing the degree of computer-supported decision-making.

a. The subjective perception of users of the value of information proves to be crucial for the degree to which a certain type of information is used.

For that reason we must try to influence the perception of school managers, by letting them experience how useful SIS-information can be in the policy-making processes they are involved in. Just as millions of people use computers for their office work because they are aware of the advantages of doing so, experiencing the added-value of computer-supported decision-making most probably will stimulate school staff to use SISs for this goal more. The best strategy to work towards that 
goal is probably to start with small projects with a high success probability. If school improvement has proven to be possible as a consequence of using computergenerated information, this most probably encourages school staff to invest more in using decision-support systems.

b. School staff do not receive too little information: the problem is that human attention and information processing capacity are scarce relative to the information available (Simon, 1993). SISs must therefore operate intelligently and do something interesting' by outputing information that is useful (e.g. because it helps to improve schools).

The nature of information influences information usage also in another way. The information SISs generate must not require time consuming retrieval and analysis, but be appealing and invite action. Modern SISs do not meet these demands yet. We therefore should attempt to build SISs that facilitate the easy production and usage of data. The barriers for retrieving and processing interesting SIS-data have to be reduced as much as possible, so that the probability that retrieved information is used will be maximized.

c. Although schools differ regarding their policy-making capacity, they in general are not considered to be very forceful policy-developers and evaluators. Since intensive computer-assisted policy-making and evaluation touches the whole school organization, it requires fundamental organizational development in many schools. Such development processes should bring schools to a level of organizational functioning that enables them to:

- decide which SIS-information they need;

- retrieve (part of) the information they need from a SIS;

- interpret the data obtained in such a way that it can be used quickly for decisionmaking;

- use the information for developing, implementing and evaluating school policy.

These activities demand a lot from schools and therefore very few schools master these skills. The complexity of decision-support in schools in general is underestimated. It is our mission to develop strategies for implementation and organizational development that prepare school staff for this comprehensive task.

Only if we are able to design and implement SISs that produce information that is interesting, easy to use and that matches the nature of schools, and if the value of these systems can be shown to school staff and we are successful in finding ways to equip for full system usage, only then might we change the nature of schooling in a fundamental way.

\section{REFERENCES}

Alkin, M.C. (1990) Debates on Evaluation. Sage Publications, Beverly Hills.

Cohen, M.D., March, J.G. and Olson, J.P. (1972) A garbage-can model of organizational choice. Administrative Science Quarterly, 17, 1-25.

Goodlad, J.I. (1975) The dynamics of educational change: toward responsive schools. McGraw-Hill, New York.

Leighwood, K.A. and Montgomery, D.J. (1982) The role of the elementary school principal in program improvement. Review of Educational Research, 52, 309-339.

Marx, E.C.H. (1975) De organisatie van scholengemeenschappen in onderwijskundige optiek. [The organization of comprehensive schools from an educational point of view]. Wolters-Noordhoff, Groningen. 
McPherson, R.B., Crowson, R. and Pitner, N.J. (1986) Managing uncertainty: administrative theory and practice in education. C.E. Merril Publishing Company, Columbus.

Mintzberg, H. (1989) Mintzberg on management. Free Press, New York.

Riehl, C., Pallas, G. and Natriello, G. (1992) More responsive high schools student information and problem-solving. Paper presented at AERA conference, SanFrancisco.

Simon, H.A. (1993) Decision making: rational, nonrational, and irrational. Educational Administration Quarterly, 29, 392-411.

Sproull, L.S. (1981) Managing education programs: a micro-behavioral analysis. Human Organization, 40, 113-122.

Sproull, L.S. and Zubrow, D. (1981) Performance information in school systems: perspectives from organization theory. Educational Administration Quarterly, 17, 61-79.

Visscher, A.J. (1991) School administrative computing: a framework for analysis. Journal of Research on Computing in Education, 24, 1-19.

Visscher, A.J. (1992) Design and evaluation of a computer-assisted management information system for secondary schools (Ph.D. dissertation). University of Twente, Enschede.

Visscher, A.J. (1995) Computer-assisted school administration and management: where are we and where should we go?, in Information Technology in Educational Management (ed. B.Z. Barta, M. Telem and Y. Gev), Chapman and Hall, London.

Weick, K.E. (1982) Administering education in loosely coupled schools. Phi Delta Kappan, 673-676.

Wild, P., Scivier, J.E. and Richardson, S.J. (1992) Evaluating information technologysupported local management of schools: the User Acceptability Audit, Educational Management and Administration, 20(1), 41-48.

Wild, P., Scivier, J. and Richardson, S. (1992) An Evaluation of a LEA's Secondary Schools IT system for LMS Support. Education Management and Administration, 20(4), 40-48.

\section{BIOGRAPHY}

A. J. Visscher received his Ph.D. at The University of Twente for his dissertation entitled "Design and Evaluation of a Computer-Assisted Management Information System for Secondary Schools". He has been working as an Assistant Professor in the Faculty of Educational Science and Technology since 1983. In collaboration with others he designed an integrated school information system (SIS) for secondary schools and evaluated its impact over a period of three years. He is the editor of two special issues of scientific journals on computerised SISs and has published numerous articles on this topic. 